\title{
Transfer as a function of stimulus selection
}

\author{
ROBERT K. YOUNG, TONY D. TEETERS AND CHARLES ZELAZNY
}

UNIVERSITY OF TEXAS

Each of 72 Ss learned two paired-as sociate lists employing compound stimuli which consisted of color-nonsense syllable combinations. For the NP groups the nonsense syllable stimuli (along with the response) conformed to an A-B, A-B paradigm of positive transfer while the colors conformed to an $\mathrm{A}-\mathrm{B}, \mathrm{A}-\mathrm{Br}$ paradigm of negative transfer. For the $\mathrm{CP}$ groups the opposite arrangement was employed so that colors conformed to an A-B, A-B paradigm and nonsense syllables conformed to an A-B, A-Br paradigm. Two levels of meaningfulness (93\% or $20 \%$ associations value nonsense syllables) were employed so that with the two control groups the design was a 2 by 3 factorial. Negative transfer was found in the NP group when nonsense meaningfulness was low while positive transfer was found in the other groups. The results indicate that stimulus selection is a function of the meaningfulness of the verbal units employed.

Several transfer studies have investigated the functional stimulus used in the learning of a pairedassociate list. Amount of facilitation in transfer is usually used to estimate the effectiveness of the nominal stimulus under consideration although Saufley \& Underwood (1964) have made inferences based on the interference observed from one list to another. In Experiment II of their study compound stimuli were used consisting of color-color name combinations. For one group the color-word combinations were constant from trial to trial (e.g., red was always printed in blue). After 15 trials, the Ss were transferred to a second list in which words and colors were identical (e.g., red was printed in red). For this group the arrangement between the lists was such that if color was used as the functional stimulus then transfer to the second list conformed to an A-B, A-B paradigm of positive transfer while if the word was used then transfer conformed to an A-B, A-Br paradigm of negative transfer. The list 2 performance of this group was poorer than that of a comparison group, indicating that some of the words were employed as stimuli in the first list.

The present experiment was designed to extend the findings of Saufley and Underwood. More specifically, color-word compound stimuli were used in paired-associate learning. In this case, however, the meaningfulness of the word was manipulated to determine the influence of this variable upon the amount of transfer in subsequent learning.

\section{Method}

The Ss were randomly assigned to two experimental conditions and one control condition. The Ss of the two experimental conditions each learned two pairedassociate lists composed of color-nonsense syllable stimuli and adjective responses. For the Ss in the CP (Color Positive) group the arrangement of the items between the two lists was such that the colors in the two lists formed with their responses an $A-B, A-B$ paradigm of positive transfer while the nonsense syllables formed an $\mathrm{A}-\mathrm{B}, \mathrm{A}-\mathrm{Br}$ paradigm of negative transfer. In the NP (Nonsense syllable Positive) group the arrangement was reversed so that the colors conformed to an $\mathrm{A}-\mathrm{B}, \mathrm{A}-\mathrm{Br}$ paradigm while the nonsense syllables conformed to an A-B, A-B paradigm. The three groups learned a common second list with first list differences defining the condition of transfer. The first list learned by the control group consisted of three-digit numbers and geometric forms as stimuli and adjectives as responses. Two levels of meaningfulness (93\% and $20 \%$ nonsense syllables) were used to bring the basic design to a 2 by 3 factorial. In addition two samples of nonsense syllables were used within each level of meaningfulness and two experimenters were employed so that the complete design is a 2 by 3 by 2 by 2 factorial ( $N=3$ per cell).

The nine pair lists were learned to a one errorless recitation criterion by the anticipation method on a Lafayette memory drum at a 2:2-sec. rate with a 4-sec. intertrial interval. Approximately $3 \mathrm{~min}$. elapsed between the learning of the two lists to allow time to change tapes and give additional instructions. The $\mathbf{7 2}$ experimentally naive Ss were taken from introductory psychology classes and assigned to groups according to a predetermined random order. Four Ss were dropped for mechanical failure or for color blindness and each was replaced by the next $S$ to appear in the laboratory.

The adjectives and nonsense syllables used in the experiment were taken from lists prepared by Melton and Glaze (Hilgard, 1951), respectively, and were as dissimilar as careful inspection would allow.

\section{Results and Discussion}

The trials to learn the first list were analyzed and no significant Fs were found. Thus, the results of this analysis do not permit the hypothesis of equivalent groups to be rejected.

The mean correct responses per trial in the six basic conditions are presented in Table 1. These data were analyzed (as were trials to criterion with essentially the same results) and it was found that conditions were significantly different with $\mathrm{F}=10.45$, $\mathrm{df}=2 / 48, p<.01$. The sum of squares for conditions was partitioned and it was found that the control group means were significantly less than the experimental group means with $\mathrm{F}=14.79$, $\mathrm{df}=1 / 48, \mathrm{p}<.01$, and that the CP group means were greater than the NP group 
Table 1.

Mean Correct Responses Per Trial During Second-List Leaming .

\begin{tabular}{ccccccc} 
Association & \multicolumn{4}{c}{ Control } & \multicolumn{2}{c}{ Condition } \\
Value & $M$ & $\mathrm{~S}$ & $\mathrm{M}^{\mathrm{M}}$ & $\mathrm{S}$ & $\mathrm{M}$ & $\mathrm{S}$ \\
\hline 93 & 5.90 & .57 & 7.28 & 1.11 & 7.54 & 1.10 \\
20 & 6.17 & .57 & 7.50 & 1.40 & 5.69 & 1.16 \\
\hline
\end{tabular}

means with $F=7.11, \mathrm{df}=1 / 48, \mathrm{p}<.05$. In addition the meaningfulness by condition interaction was significant with $F=8.60, d f=2 / 48, p<.01$. The sum of squares associated with this interaction was partitioned and it was found that the meaningfulness by $\mathrm{E}$ vs. $\mathrm{C}$ interaction was significant with $F=4.59, \mathrm{df}=1 / 48, \mathrm{p}<.05$ as was the meaningfulness by NP vs. CP interaction, with $F=12.60, \mathrm{df}=1 / 48, \mathrm{p}<.01$. No other $\mathrm{Fs}$ were significant in the analysis.

The meaning of the significant main effects and interactions can be seen from Table 1. That is, the CP groups and the 93\% NP group showed significant positive transfer with F's of $9.65,10.34$, and $4.55(\mathrm{df}=1 / 48)$, $\mathrm{p}<.01$, while the $20 \% \mathrm{NP}$ group showed negative transfer. This latter difference was not significant although significant negative transfer was found in the analysis of trials to learn: the $20 \%$ NP group took 12.83 trials to criterion while its control took only 6.33 trials with $F=6.15, \mathrm{df}=1 / 16, \mathrm{p}<.05$.

The results of the present experiment indicate that choice of functional stimulus is closely related to the meaningfulness of the verbal materials employed. As the meaningfulness of the verbal units decreased second-list performance on the NP list also decreased until performance on this list was poorer than on the control. On the other hand, performance on the CP list was relatively unaffected by a change in the meaningfulness of the verbal material with both high and low meaningful conditions yielding significant positive transfer.

These results can be interpreted as indicating that a decrease in the use of the nonsense syllable as the functional stimulus occurred from the high to low meaningfulness conditions. Furthermore, the negative transfer found in the $20 \%$ NP condition indicated that in this condition colors were almost uniformly selected as the functional stimuli-if they had not been some small amount of positive transfer would have been obtained. Under high meaningfulness conditions colors and nonsense syllables were both used as the functional stimulus as indicated by the significant positive transfer obtained by both groups.

The results of the present study are in general agreement with other studies, e.g., Underwood, Ham, \& Ekstrand (1962), investigating the role of the functional stimulus in paired-associate learning. The results also indicate that the method employed by Saufley \& Underwood (1964) is an effective method for use in this area.

\section{References}

Hilgard, E. R. Methods and procedures in the study of learning. In S. S. Stevens (Ed.), Handbook of experimental psychology. New York: Wiley, 1951.

Saufley, W. H., \& Underwood, B. J. Cue selection interference in paired-associate learning. J. verbal Learn. verbal Behav., 1964 $3,474-479$.

Underwood, B. J., Ham, M., \& Ekstrand, B. Cue selection in pairedNote

1. The research reported in the present study was supported in part by Grant GB 3629 from the National Science Foundation to David T. Hakes and the senior author. 